\title{
Review of world genera of Ceinae, with the description of two new Palaearctic species of Spalangiopelta Masi (Hymenoptera, Chalcidoidea, Pteromalidae)
}

\author{
Mircea-Dan MITROIU \\ "Alexandru Ioan Cuza" University Iaşi, Faculty of Biology, \\ Bd. Carol I 20A, 700505 Iaşi, Romania. \\ Email: mircea.mitroiu@,uaic.ro
}

urn:1sid:zoobank.org:author:B0B8F42E-15B8-4E2C-91C5-2EB4D1AE6DD7

\begin{abstract}
The paper provides the first illustrated key to all described genera of Ceinae, i.e., Bohpa Darling, 1991, Cea Walker, 1837, and Spalangiopelta Masi, 1922. Based on the study of the original material, the genus Diparisca Hedqvist, 1964 stat. nov. is removed from the synonymy with Spalangiopelta and its higher classification is discussed. Spalangiopelta rameli $\mathrm{sp}$. nov. and $S$. viridis $\mathrm{sp}$. nov. are described from Greece and the Canary Islands, respectively.
\end{abstract}

Keywords. Bohpa, Cea, Diparisca, Spalangiopelta, new species, parasitoid.

Mitroiu M.-D. 2016. Review of world genera of Ceinae, with the description of two new Palaearctic species of Spalangiopelta Masi (Hymenoptera, Chalcidoidea, Pteromalidae). European Journal of Taxonomy 251: 1-15. http://dx.doi.org/10.5852/ejt.2016.251

\section{Introduction}

Ceinae is a small subfamily of chalcid wasps, currently classified in the polyphyletic family Pteromalidae. According to Noyes (2015) there are three described genera of Ceinae in the world: Bohpa Darling, 1991, Cea Walker, 1837, and Spalangiopelta Masi, 1922. The monotypic genus Bohpa contains the only Afrotropical species of Ceinae, the brachypterous B. maculata Darling, 1991, described from South Africa. The monotypic genus Cea consists of the West Palaearctic species C. pulicaris Walker, 1837.

Spalangiopelta Masi, 1922 is the most speciose genus, with 13 extant species: S. alata Bouček, 1953 (West Palaearctic), S. albigena Darling, 1991 (Nearctic, Neotropical), S. alboaculeata Darling, 1995 (West Palaearctic), S. apotherisma Darling \& Hanson, 1986 (Nearctic), S. brachyptera Masi, 1922 (West Palaearctic), S. canadensis Darling, 1991 (Nearctic), S. ciliata Yoshimoto, 1977 (Nearctic), S. dudichi Erdős, 1955 (West Palaearctic), S. felonia Darling \& Hanson, 1986 (Nearctic), S. ferrierei (Hedqvist, 1964) (Neotropical), S. hiko Darling, 1995 (East Palaearctic), S. laevis Darling, 1991 (Neotropical), and S. procera Graham, 1966 (West Palaearctic), plus one fossil species: S. georgei Darling, 1997 (Masi 1922; Bouček 1953; Erdős 1955; Hedqvist 1964; Graham 1966; Yoshimoto 1977; Darling 1991b, 1995, 1997; Darling \& Hanson 1986). 
Of all species of Ceinae hosts are known only for Cea pulicaris and Spalangiopelta alata and include small Diptera from the families Agromyzidae and Drosophilidae, respectively (Noyes 2015).

In this study, two new West Palaearctic species of Spalangiopelta are described, and S. ferrierei is transferred back to Diparisca Hedqvist, 1964 which is removed from the synonymy with Spalangiopelta. The taxonomic position of Diparisca is also briefly discussed.

\section{Material and methods}

As pointed out by Darling (1991b) specimens of Spalangiopelta are usually extremely rare in collections. All specimens of the new species have been collected using Malaise traps (MT) and / or yellow pan traps (YPT), which are usually the only methods that potentially yield series of specimens. Prior to mounting on rectangular cards, specimens were dried using hexamethyldisilazane (HMDS).

The terminology used in this paper follows Darling (1991b) and Gibson (1997), except for the terms mesoscutellum and metascutellum, which are used for scutellum and dorsellum, respectively. A character used to separate some species groups of Spalangiopelta is the presence or absence of a "hyaline break" on the fore wing parastigma (Darling 1991b: 15, fig. 35).

For the new species, a description of the holotype and allotype is given, followed by a discussion of variation found among paratypes. The description format follows Darling (1991b) in order to allow easy comparisons among the new and previously described species. The differential diagnoses for the new species encompass the characters used by Darling (1991b) to separate the world species of Spalangiopelta and are intended to allow the separation of the new species from the previously described ones as well as from each other. Colour of the eyes and ocelli should be used with care, since it seems to vary according to the methods used for the preservation and preparation of specimens.

Observations and descriptions were made using an Olympus SZX9 stereo microscope. Measurements were taken with a micrometric graduated ocular. Images were taken using a Leica DFC500 digital camera attached to a Leica M205A automated research stereomicroscope. The images were then processed with Zerene Stacker ${ }^{\circledR}$. Their clarity was further enhanced using Adobe ${ }^{\circledR}$ Photoshop ${ }^{\circledR}$ 7.0.

\section{The following abbreviations are used in the text and figures}

$\begin{array}{ll}\text { A1-A3 } & =\text { anelli } \\ \text { C1-C3 } & =\text { claval segments } \\ \text { F1-F5 } & =\text { funicular segments } \\ \text { GT1-GT7 } & \text { gastral tergites } \\ \text { HL } & =\text { head length } \\ \text { HW } & =\text { head width } \\ \text { M } & =\text { marginal vein } \\ \text { MSP } & =\text { mesopleuron } \\ \text { P } & =\text { postmarginal vein } \\ \text { S } & =\text { stigmal (or radial) vein } \\ \text { SM } & =\text { submarginal vein } \\ \text { SP } & =\text { spiracle }\end{array}$

The scape is measured without the radicle. The pedicel is measured in lateral view. The mesosoma and metasoma are measured in lateral view, the latter without including the ovipositor sheaths.

\section{Institutional abbreviations}

$\mathrm{BMNH}=$ Natural History Museum, London, UK

$\mathrm{CNC}=$ Canadian National Collection of Insects, Agriculture and Agri-Food Canada, Ottawa, ON, Canada 

MICO = Mitroiu Collection, "Alexandru Ioan Cuza" University of Iaşi, Faculty of Biology, Romania
MNCN $=$ Museo Nacional de Ciencias Naturales, Madrid, Spain

\title{
Results
}

\author{
Class Hexapoda Blainville, 1816 \\ Order Hymenoptera Linnaeus, 1758 \\ Suborder Apocrita Latreille, 1810 \\ Superfamily Chalcidoidea Latreille, 1817 \\ Family Pteromalidae Dalman, 1820
}

Subfamily Ceinae Bouček, 1961

\section{Key to world genera of Ceinae}

1. Mesosoma with long pronotum, but very short mesoscutum, mesoscutellum and propodeum, the latter very steep; metasoma sessile (Fig. 1B); female brachypterous, male unknown; body colour yellowish (Fig. 1A-B)

Bohpa Darling, 1991

- Mesosoma with shorter pronotum, but more elongate mesoscutum, mesoscutellum and propodeum, the latter not steep; metasoma with distinct although usually transverse petiole (Figs 2E, 3E); female brachypterous (Fig. 2B) or macropterous (Figs 2A, 3A, 4A), males macropterous (Figs 2D, 4E); body colour usually with distinct metallic reflections (Figs 2-4) ................

2. Posterior margin of mesopleuron not expanded posteriorly, not overlapping metapleural/ propodeal complex (Fig. 2E); if macropterous, female fore wing with two brown bands (Fig. 2A); male antenna with regular pilosity (Fig. 2D) ....................Cea Walker, 1837

- Posterior margin of mesopleuron expanded posteriorly, clearly overlapping metapleural/ propodeal complex (Fig. 3E); if macropterous, female fore wing broadly infumate or hyaline (Figs 3D, 4D); male antenna with each funicular segment bearing whorl of long setae (Fig. 4F)

Fig. 1

Bohpa Darling, 1991: 623-624. Type species: B. maculata Darling, 1991, by original designation and monotypy.
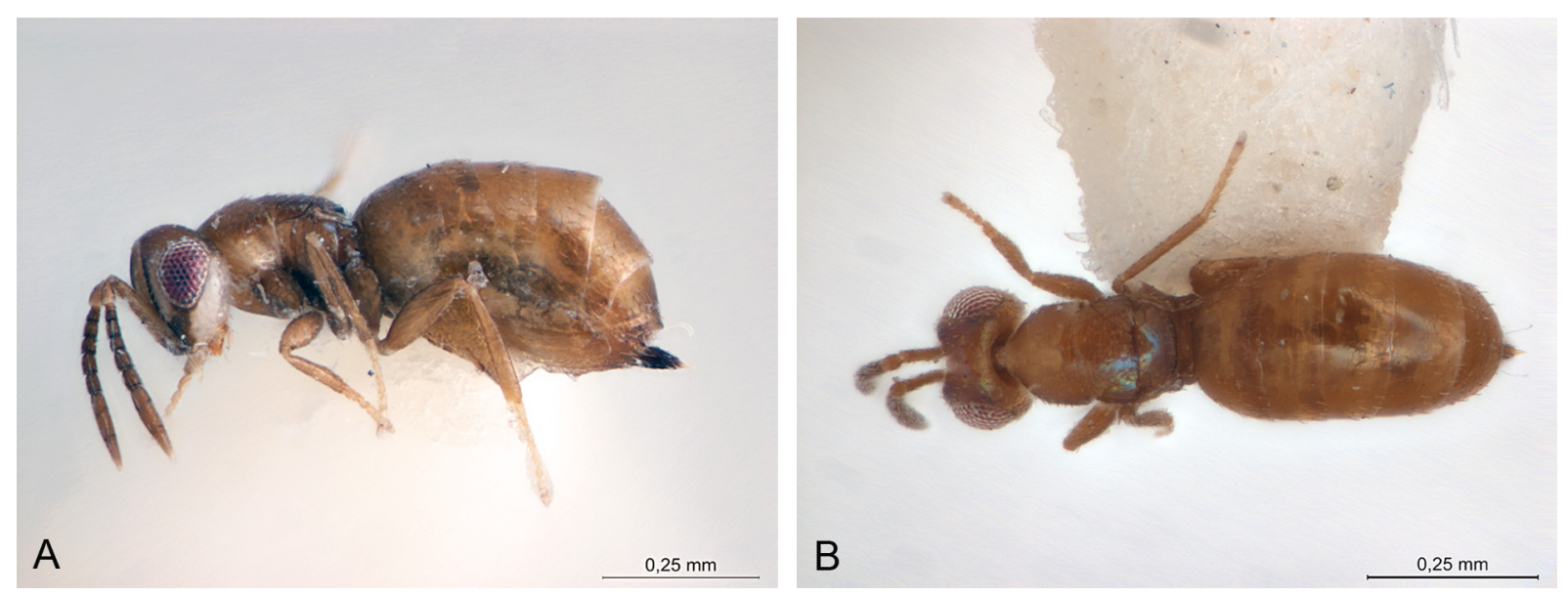

Fig. 1. Bohpa maculata,, , paratype: A. Habitus in lateral view. B. Habitus in dorsal view. 


\section{Diagnosis}

Female (male unknown)

Mesosoma with long pronotum and very short mesoscutum, mesoscutellum and propodeum, the latter very steep; metasoma sessile (Fig. 1B); brachypterous; the only species known with body colour yellowish (Fig. 1A-B).

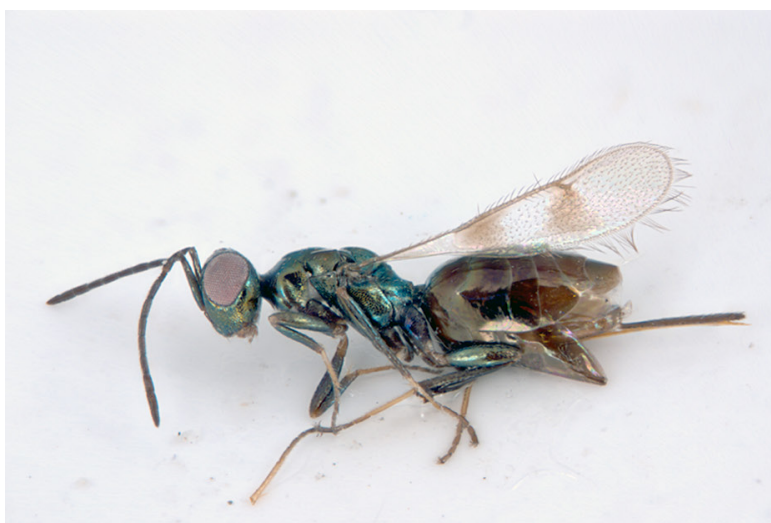

A

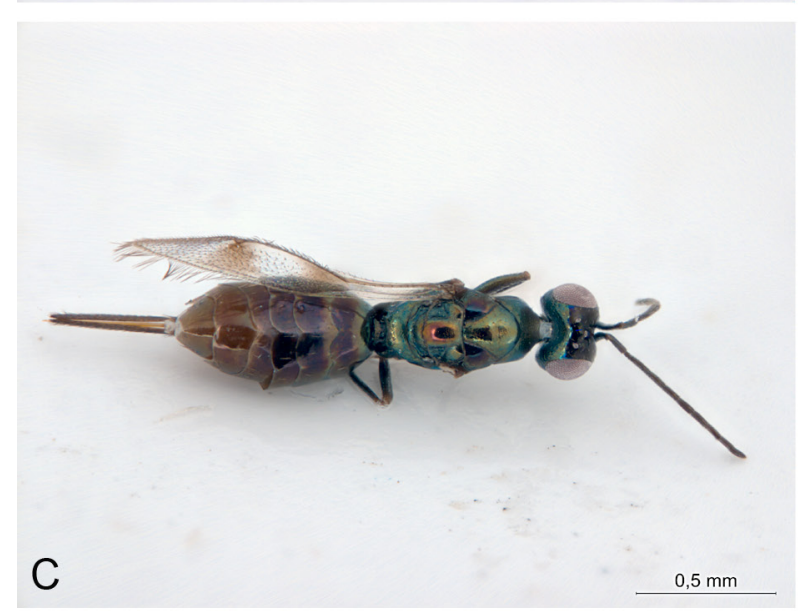

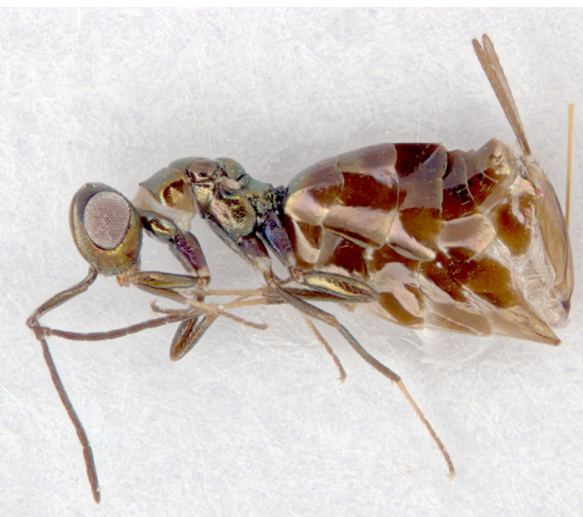

B

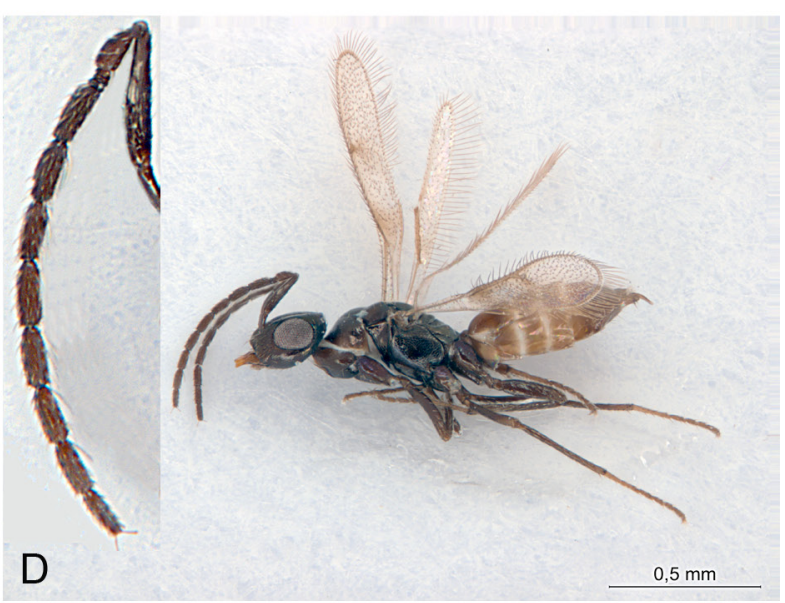

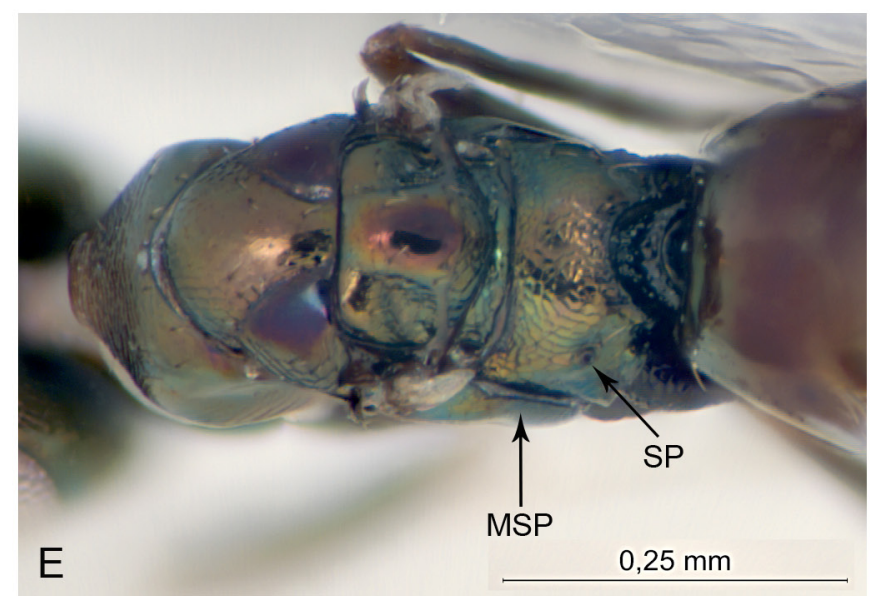

Fig. 2. Cea pulicaris Walker, 1837. A. Macropterous $q$ (Slovakia), habitus in lateral view. B. Brachypterous $\odot$ (Greece), habitus in lateral view. C. Macropterous $q$ (Slovakia), habitus in dorsal view. D. $\hat{\delta}$ (Greece), habitus in lateral view (insert: antenna in lateral view). E. Brachypterous $q$ (Greece), mesosoma in dorsal view. 
Genus Cea Walker, 1837

Fig. 2

Cea Walker, 1837: 355. Type species: C. pulicaris Walker, 1837, by monotypy.

\section{Diagnosis}

\section{Both sexes}

Mesosoma with short pronotum and moderately long mesoscutum, mesoscutellum and propodeum, the latter not steep (Fig. 2E); metasoma with distinct although usually transverse petiole (Fig. 2E); body colour with distinct metallic reflections (Fig. 2); posterior margin of mesopleuron not expanded posteriorly, not overlapping metapleural/propodeal complex (Fig. 2E).

\section{Female}

Macropterous (Fig. 2A) or brachypterous (Fig. 2B); if macropterous, fore wing with two brown bands (Fig. 2A).

Male

Macropterous (Fig. 2D); antenna with regular pilosity (Fig. 2D).

Genus Spalangiopelta Masi, 1922

Figs 3-4

Spalangiopelta Masi, 1922: 169. Type species: S. brachyptera Masi, 1922, by monotypy.

\section{Diagnosis}

\section{Both sexes}

Mesosoma with short pronotum and moderately long mesoscutum, mesoscutellum and propodeum, the latter not steep (Figs 3E, 4G); metasoma with distinct although usually transverse petiole (Figs 3E, $4 \mathrm{G}$ ); body colour usually with distinct metallic reflections (Figs 3-4); posterior margin of mesopleuron expanded posteriorly, clearly overlapping metapleural/propodeal complex (Figs 3E, 4G).

\section{Female}

Brachypterous or macropterous (Figs 3A, 4A); if macropterous, fore wing broadly infumate or hyaline (Figs 3D, 4D).

\section{Male}

Macropterous (Fig. 4E); antenna with each funicular segment bearing whorl of long setae (Fig. 4F).

Spalangiopelta rameli sp. nov. urn:1sid:zoobank.org:act:7EA6FFD7-46B8-44A6-A686-EF8C01136E3B

Fig. 3A-E

\section{Diagnosis}

\section{Female}

Head and mesosoma mostly with moderately strong bronze-green metallic reflections, metasoma dark brown (Fig. 3A-B); antenna dark brown (Fig. 3C); coxae, trochanters and femora dark brown, tibiae and tarsi lighter (Fig. 3A); gena without white maculation (Fig. 3C); mesosoma moderately robust, length about $1.7 \times$ width; malar sulcus present but hardly visible; scape linear in lateral view (Fig. $3 \mathrm{C}$ ); F1 length $1.60-1.85 \times$ width; mesosoma width $0.95 \times$ head width; midlobe of mesoscutum with imbricate sculpture; fore wing with admarginal setae, parastigma without hyaline break (Fig. 3D); metascutellum 
slightly longer than frenum (Fig. 3E); petiole transverse; ovipositor sheaths moderately protruding, slightly less than $1 / 2$ length of hind tibia (Fig. 3A).

\section{Male}

Unknown.

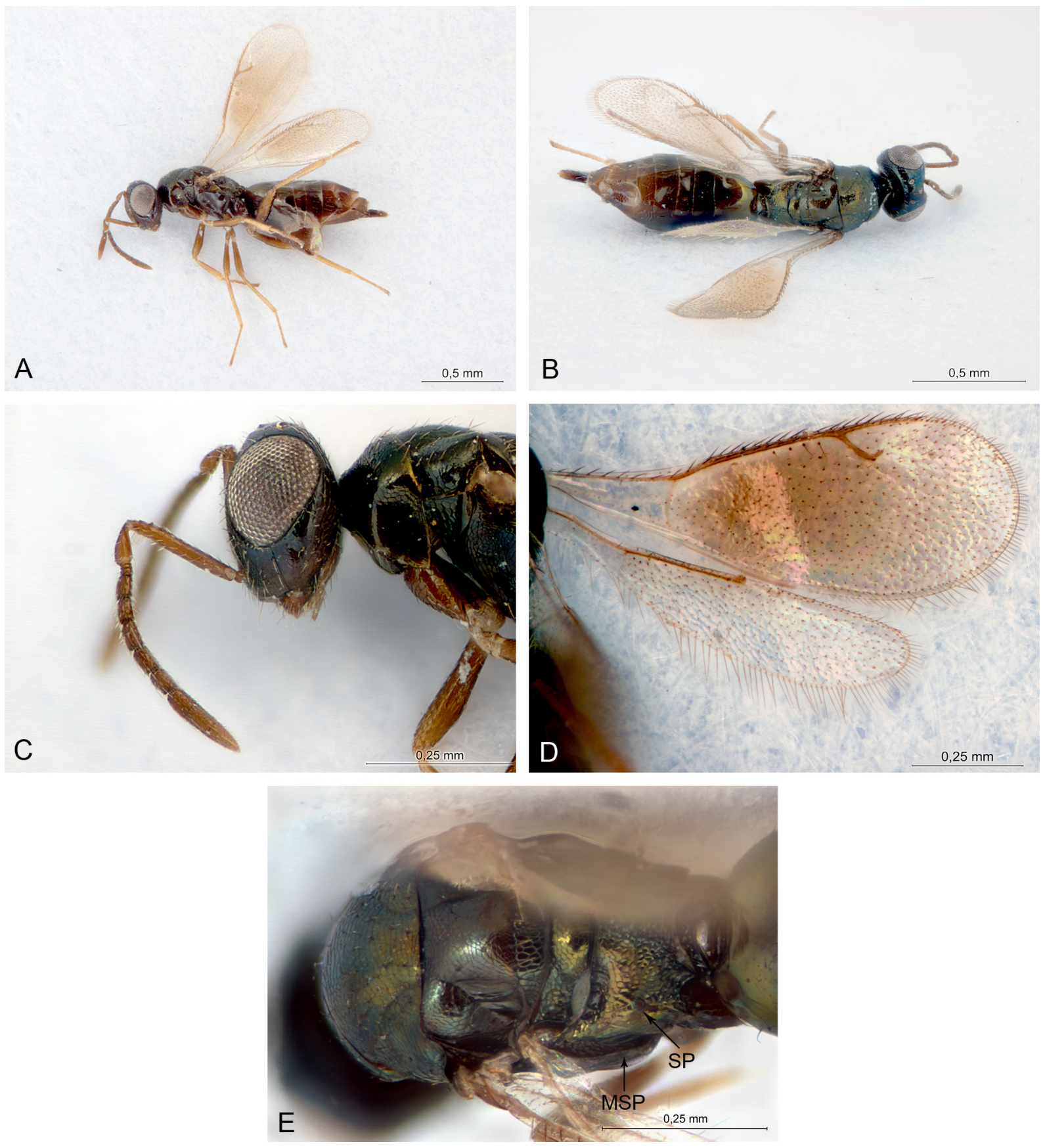

Fig. 3. Spalangiopelta rameli sp. nov. A. $\uparrow$, holotype, habitus in lateral view. B. + , holotype, habitus in dorsal view. C. + , holotype, head and anterior part of mesosoma in lateral view. D. + , holotype, wings. E. + , paratype, mesosoma in dorsal view (MICO). 


\section{Etymology}

The species epithet is dedicated to Gordon Ramel, who collected the specimens during an extensive entomological survey in Kerkini, Greece.

\section{Type material}

\section{Holotype}

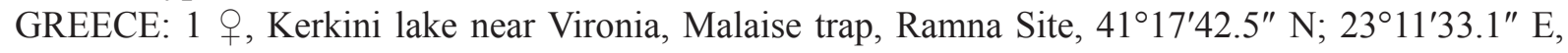
$750 \mathrm{~m}$ asl, 13 Oct. -19 Oct. 2008, leg. Gordon Ramel (BMNH).

\section{Paratypes}

GREECE: 1 , as holotype, except 29 Oct.-5 Nov. 2008 (MICO); 1 , , Kerkini lake near Promahonas;

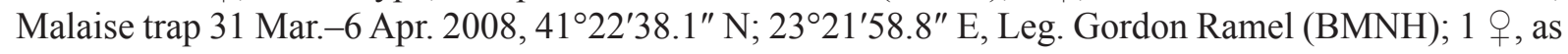
previous, except 17-23 Mar. 2008 (MICO).

\section{Description}

\section{Female holotype}

BoDy LENGTH. $1.8 \mathrm{~mm}$.

Colour. Head black, with bluish reflections (Fig. 3B); mandibles reddish brown, palpi brown; antenna dark brown (Fig. 3C); eyes and ocelli pale grey (Fig. 3A-B). Mesoscutum with bronze-green reflections; mesoscutellum except frenum dark brown, with slight greenish metallic reflections; frenum, metascutellum and propodeum with bronze-green reflections (Fig. 3B, cf. Fig. 3E); coxae, trochanters and femora dark brown, tibiae and tarsi lighter (Fig. 3A); tegula and wing venation brown, parastigma without hyaline break; fore wing disc broadly and moderately infumate; hind wing hyaline (Fig. 3D). Metasoma mainly dark brown, slightly metallic basally, distal third lighter; ovipositor sheaths dark brown (Fig. 3A-B). Body setation light brown.

HEAD. In dorsal view moderately transverse, $\mathrm{HW} / \mathrm{HL}=1.7$. Sculpture imbricate, except scrobal cavity mainly smooth with striate lateral sides. $\mathrm{MS} / \mathrm{EH}=0.4$. Malar sulcus present but hardly visible (Fig. $3 \mathrm{C}$ ). Antenna (Fig. 3C): A3 wider than long, length about equal to A1+A2; F1 conical, length $1.85 \times$ width, distally wider than anelli. F2-F5 distinctly longer than wide, subequal in length to F1, but wider than the latter. Clava about as wide as distal funicular segments, length about $5.5 \times$ width, about $1.1 \times$ longer than F3-F5. C1 subequal to F5, C2-C3 gradually increasing in length.

Mesosoma. Length about $1.7 \times$ width. Dorsum moderately arched in lateral view (Fig. 3A). Sculpture imbricate, almost indistinct on disc of mesoscutellum. Notauli distinct, complete. Pronotum about $0.8 \times$ length of mesoscutum. Mesoscutellum subequal in length to mesoscutum. Axillula with one longitudinal costa in the middle. Frenum distinct (cf. Fig. 3E). Metanotum about $1 / 3$ length of mesoscutellum. Metascutellum distinctly delimited, width about $2.5 \times$ length, slightly longer than frenum (cf. Fig. 3E). Propodeum about $0.6 \times$ as long as mesoscutellum, distinctly reticulate, reticulation coarser on nucha; propodeum raised along median line but without distinct carinae, with two elongate foveae laterad along metanotum and one very shallow depression posterior to each spiracle (cf. Fig. 3E). Prepectus narrowly triangular, with imbricate sculpture. Mesopleuron mostly with very fine imbricate sculpture except on shallowly reticulate mesepisternum. Fore wing (Fig. 3D) length about $2.8 \times$ width, the longest apical setae (fringe) shorter than stigmal vein, with 4 admarginal setae below marginal vein. Parastigma without hyaline break. SM:M:S:P= $63: 48: 14: 27$. Stigmal vein almost straight, stigma hardly enlarged, uncus long. Hind wing length about $4.8 \times$ width, longest apical setae slightly less than half width of hind wing.

Metasoma. Ovate-acuminate (Fig. 3B). Petiole transverse, mostly concealed under nucha, with longitudinal costae. Gaster mostly smooth, shiny, with at most extremely fine imbricate sculpture on 
distal tergites, length without ovipositor sheaths slightly more than twice width. GT1 longer than GT2GT3 combined. Ovipositor sheaths about $0.4 \times$ as long as hind tibia (Fig. 3A-B).

\section{Male \\ Unknown. \\ Variation \\ Females}

Body length: $1.6-1.8 \mathrm{~mm}$. F1 length $1.60-1.85 \times$ width, distally slightly to distinctly wider than A3. Each of the following funicular segments subequal to or longer than F1. Clava length about 5.0-5.5 $\times$ width. Fore wing length about $2.8-2.9 \times$ width, with $4-8$ admarginal setae arranged in $1-2$ rows. M about $1.6-1.9 \times \mathrm{P}$ and 3.4-4.0 $\times$ S. Gaster length about $1.8-2.1 \times$ width. The specimens collected near Vironia differ from those collected near Promahonas in being larger and having the F1 subequal in length to any of the following funicular segments; the latter specimens are smaller, and F1 is distinctly shorter than any of the following segments; these differences are regarded as intraspecific variability.

\section{Distribution}

Greece.

\section{Hosts}

Unknown.

\section{Remarks}

This species appears to be intermediate between $S$. procera and $S$. dudichi, due to its moderately robust mesosoma. From both species it differs mainly in having distinctly shorter ovipositor sheaths and a different general body colour. Additionally, from $S$. dudichi it differs in having a longer F1.

\section{Spalangiopelta viridis sp. nov. urn:1sid:zoobank.org:act:DA98A7F1-1631-429E-A97E-ABDAB4FC3C71}

Fig. $4 \mathrm{~A}-\mathrm{G}$

\section{Diagnosis}

\section{Both sexes}

Head and mesosoma mostly with bright green and some violet and bronze metallic reflections (the first less strong in males), metasoma dark brown; antenna brown; legs mostly dark yellow, fore coxa usually darker (Fig. 4A-B, E); gena without pale maculation (Fig. 4C); mesosoma moderately robust, length $1.65 \times$ width; malar sulcus indistinct (Fig. 4C); wings well developed (Fig. 4A-B).

\section{Female (Fig. 4A-D, G)}

Scape liniar in lateral view; F1 length about $1.3 \times$ width; mesosoma width $0.95 \times$ head width; midlobe of mesoscutum mainly with imbricate sculpture; fore wing with admarginal setae, parastigma without hyaline break; metascutellum about as long as frenum; petiole transverse; ovipositor sheaths short, less than $1 / 3$ length of hind tibia.

\section{Male (Fig. 4E-F)}

Petiole conical; fore wing linear, front and hind margins parallel from middle of marginal vein to end of postmarginal vein; fore wing with 2-4 admarginal setae below marginal vein, without hyaline break. 

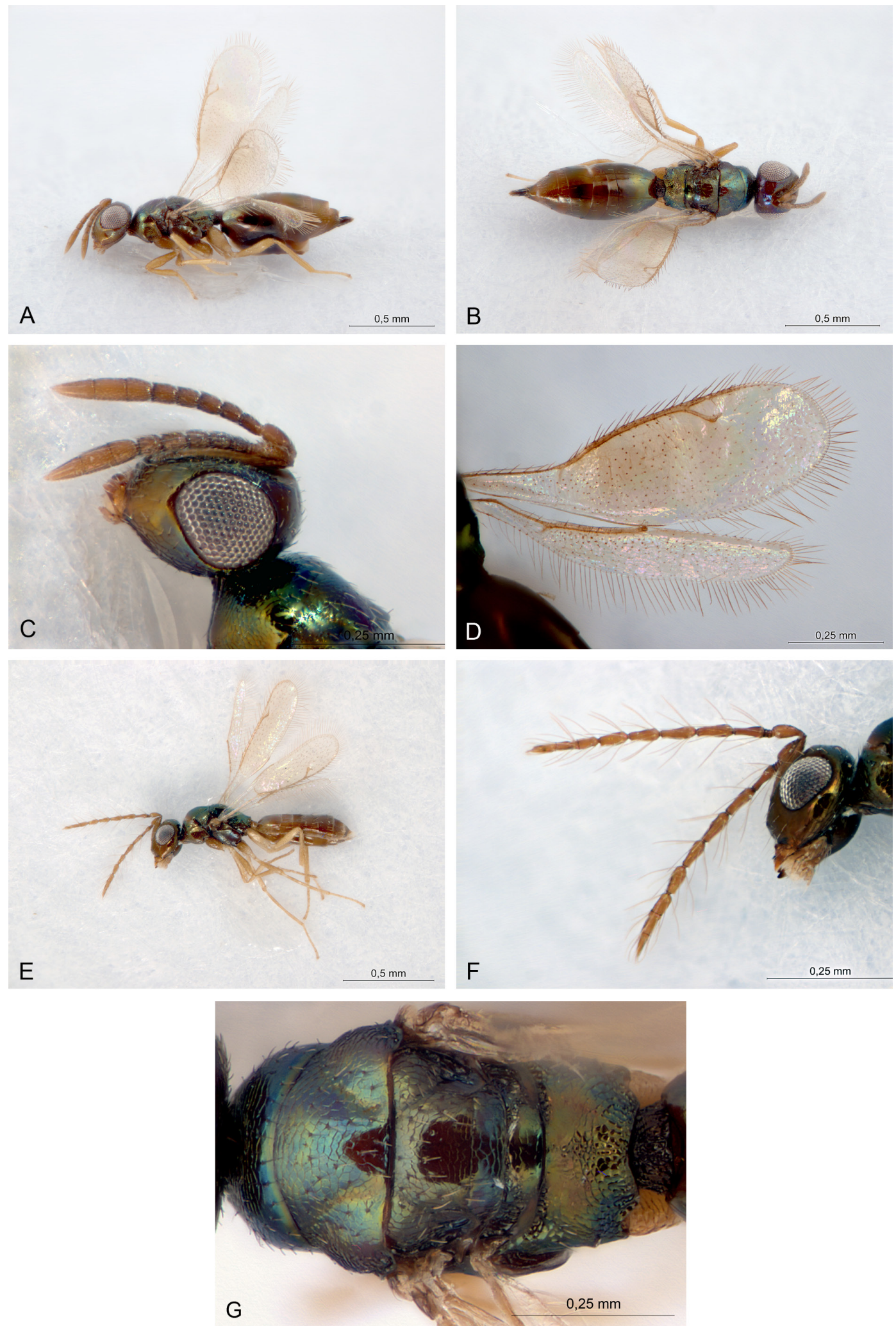

Fig. 4. Spalangiopelta viridis sp. nov. A. $\odot$, holotype, habitus in lateral view. B. $\odot$, holotype, habitus in dorsal view. C. + , holotype, head and antennae in lateral view. D. $\odot$, holotype, wings. E. $\curvearrowright$, allotype, habitus in lateral view. F. $\curvearrowright$, allotype, head and antennae in lateral view. G. + , holotype, mesosoma and petiole in dorsal view. 


\title{
Etymology
}

The species epithet refers to the main body colour, which is usually bright green.

\section{Type material}

\section{Holotype}

SPAIN: , P.N. Caldera de Taburiente, La Palma (Islas Canarias), Roque de la Cumbrecita, 1377 m, Malaise trap, 28RBS2177-1, M4, 12 Jul. 2000, T. Domingo Quero leg. (MNCN).

\author{
Allotype \\ SPAIN: 1 , P.N. Caldera de Taburiente, La Palma (Islas Canarias), Roque de la Cumbrecita, Malaise \\ trap, 1377 m, 28RBS2177-1, M4, 19 Jul. 2000, T. Domingo Quero leg. (MNCN).
}

\section{Additional paratypes}

SPAIN: 1 , data as holotype (MNCN); 1 , data as holotype, except yellow trap, YT4 (MICO); 1 ,

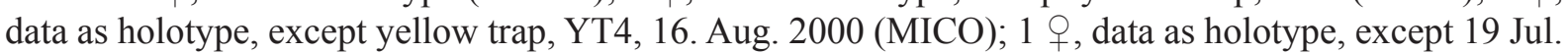

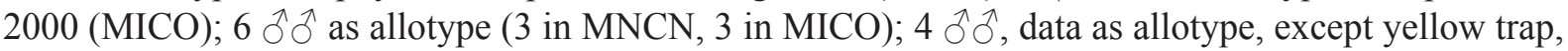

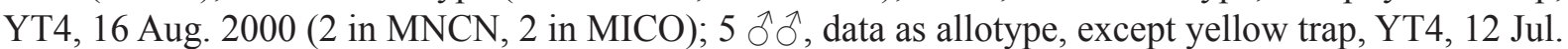
2000 ( 3 in MNCN, 2 in MICO); 2 $\widehat{\partial}$, data as allotype, except 12 Jul. 2000 (1 in MNCN, 1 in MICO).

\section{Description}

\section{Female holotype}

BODY LENGTH. $1.75 \mathrm{~mm}$.

CoLour. Head bronze-green, with violet reflections on upper face and vertex (Fig. 4A-C); mandibles light brown, teeth darker; palpi light brown; antenna brown, except scape light brown; eyes and ocelli pale grey (Fig. 4C). Mesosoma mainly bright green, except propodeum golden green (Fig. 4A-C, G); fore coxa light brown, mid and hind coxae dark yellow; trochanters yellow; fore femora brownish yellow; mid and hind femora, and all tibiae and tarsi dark yellow (Fig. 4A); tegula and wing venation light brown, parastigma without hyaline break; fore wing disc broadly but slightly infumate; hind wing hyaline (Fig. 4D). Metasoma, including ovipositor sheaths, mainly dark brown, slightly metallic basally; petiole dark green (Fig. 4A-B). Body setation pale.

HEAD. In dorsal view moderately transverse, $\mathrm{HW} / \mathrm{HL}=1.7$. Sculpture finely imbricate, except smooth scrobal cavity and area around ocelli. $\mathrm{MS} / \mathrm{EH}=0.5$. Malar sulcus indistinct (Fig. 4C). Antenna (Fig. 4C): A3 wider than long, length about equal to A2; A1 indistinct; F1 cylindrical, length about $1.3 \times$ width, distally very slightly wider than anelli. F2-F5 distinctly longer than wide, subequal in length, but wider than F1. Clava wider than distal funicular segments, length about $4.4 \times$ width, subequal in length to F2F5. C1 about equal to F5, C2-C3 gradually increasing in length.

Mesosoma. Length $1.65 \times$ width. Dorsum moderately arched in lateral view (Fig. 4A). Sculpture very fine, mostly imbricate. Notauli distinct, complete, although not deeply impressed. Pronotum about $0.9 \times$ length of mesoscutum. Mesoscutellum about $0.9 \times$ as long as mesoscutum. Axillula shallowly reticulate, without longitudinal costae. Frenum distinct, sculpture less fine than on mesoscutellum disc. Metanotum about $1 / 3$ length of mesoscutellum. Metascutellum virtually smooth, distinctly delimited, width about twice length, subequal in length to frenum (Fig. 4G). Propodeum about $0.7 \times$ as long as mesoscutellum, distinctly reticulate except near metanotum where almost smooth; propodeum not raised along median line, without any carinulae, with two lateral grooves along metanotum. Prepectus narrowly triangular, with shallow reticulation. Mesopleuron mostly with very fine imbricate sculpture, including mesepisternum. Fore wing (Fig. 4D) length about $3.4 \times$ width, the longest apical setae (fringe) longer than stigmal vein, with 4 admarginal setae below marginal vein. Parastigma without hyaline break. SM: 
$\mathrm{M}: \mathrm{S}: \mathrm{P}=55: 40: 10: 18$. Stigmal vein almost straight, stigma hardly enlarged, uncus long. Hind wing length about $5.8 \times$ width, longest apical setae slightly less than width of hind wing.

Metasoma. Ovate-acuminate (Fig. 4B). Petiole transverse, coriaceous, without longitudinal rugae (Fig. 4G). Gaster mostly smooth, shiny, with at most extremely fine imbricate sculpture on distal tergites, length without ovipositor sheaths about $2.2 \times$ width. GT1 almost equal to GT2-GT4 combined. Ovipositor sheaths about $0.3 \times$ as long as hind tibia (Fig. 4A).

\section{Male allotype}

Differs from the female holotype as follows. Body length: $1.25 \mathrm{~mm}$. Head colour lighter, violet reflections less strong (Fig. 4E). Propodeum with golden reflections less strong; both fore and mid coxae brown, rest of leg segments brownish yellow (Fig. 4E). Petiole brown. Antenna (Fig. 4F): A1 visible, although strongly transverse; A2 and A3 transverse, subequal in length; each funicular segment with one basal whorl of erect setae that are longer than the segments; F1 length about $3 \times$ width, F2 slightly longer than F1, F3 subequal in length to F1, F4 and F5 slightly shorter than F3; clava length about $5 \times$ width, longer than F4-F5 combined. Petiole longer, conical, almost smooth. Infumation on fore wing less conspicuous; fore wing linear, front and hind margins parallel from middle of marginal vein to end of postmarginal vein (Fig. 4E); fore wing length about $4 \times$ width. $S M: M: S: P=50: 33: 7: 18$. Gaster length about $2.3 \times$ width, slightly and gradually widening toward apex in dorsal view.

\section{Variation}

\section{Females}

Body Length. 1.40-1.75 mm. F1 length 1.1-1.3× width. Clava length about 4.2-4.4× width. Fore wing length about 3.4-3.7× width, with 3-4 admarginal setae below marginal vein, some almost touching the

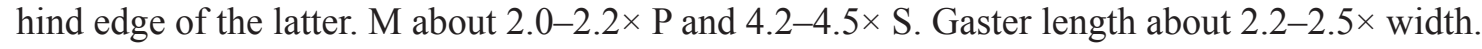

\section{Males}

BODY LENGTH. $0.90-1.25 \mathrm{~mm}$. In small specimens metallic colours fainter, probably because of thinner cuticle (head and flagellum sometimes collapsing even after HMDS treatment) and alcohol preservation in light conditions. F1 length about 2.4-3.0× width, F2 slightly longer than F1, F3 subequal in length to F1 or F2, F4 and F5 from slightly shorter to about equal to F3. Clava length about 5-6× width. Fore wing length about $4.0-4.5 \times$ width, with $2-4$ admarginal setae below marginal vein. M about $1.7-1.8 \times \mathrm{P}$ and $4.3-4.7 \times$ S. Gaster length about $2.3-2.5 \times$ width.

\section{Distribution}

Canary Islands.

\section{Hosts}

Unknown.

\section{Remarks}

This is one of the few species of Spalangiopelta with bright metallic colours. Following Darling's key (1991b), S. viridis sp. nov. most closely resembles S. brachyptera, from which it differs mainly in the well developed wings, and different colour of antennae and body.

\section{Discussion}

According to Darling (1991a, 1991b), the members of Ceinae share the following combination of characters: clypeus reduced; mandibles bidentate; antennae inserted very low, antennal formula 11353 (Figs 3C, 4C); notauli complete; propodeal spiracle situated half-way between anterior and posterior 
margins of propodeum (Figs 2E, 3E, 4G); marginal vein long (Figs 2A, 3D, 4D). According to Desjardins (2007: 26), if Bohpa were excluded from the phylogenetic analysis, "Ceinae would be resolved as monophyletic based on five synapomorphies, only the first of which is not homoplastic: presence of claval peg-like sensilla, first funicular segment subequal in length to pedicel, presence of admarginal setae, marginal vein long, and toruli within 1 torulus diameter from the oral fossa".

The highly modified morphology of Bohpa (Fig. 1A-B) makes its classification difficult. Its taxonomic position is discussed in detail by Desjardins (2007), who concluded that its inclusion in the analysis made the Ceinae paraphyletic. However, taking into consideration that it cannot be included in Diparinae either (it lacks most of the synapomorphies that define Diparinae), until further evidence, its present classification in Ceinae is maintained.

The monotypic genus Diparisca Hedqvist, 1964 stat. nov. (Fig. 5A-D), described from Brazil, is removed from synonymy with Spalangiopelta, based on the examination of the holotype, one paratype and several other specimens of $D$. ferrierei Hedqvist, 1964 from BMNH. The synonymy was proposed by Desjardins (2007: 82), who stated that the "holotype specimen has been examined and conclusively identified as Spalangiopelta". It is assumed that the above assertion was based on the raised mesopleuron of Diparisca, which is similar to the mesopleuron structure in Spalangiopelta (Fig. 5C). However, the vertex and mesosoma of Diparisca are covered with strong paired setae (Fig. 5A-D), the propodeal spiracles are more advanced, the metascutellum is not smooth and convex (Fig. 5C), the mesoscutellum is much higher, and the cuticle is rather strongly sclerotized. At the same time, it is also clear that Hedqvist's description of Diparisca is partly inadequate: the female antenna (Fig. 5D) has three anelli not two, and the clava consists of three segments and not one (although their limits are very difficult to observe because of the pale colour). Thus, the correct antennal formula in female Diparisca is 11353. Hedqvist (1964: 56) stated that Diparisca was "habitually like Grahamisia Del. [= Dipara Walker] but
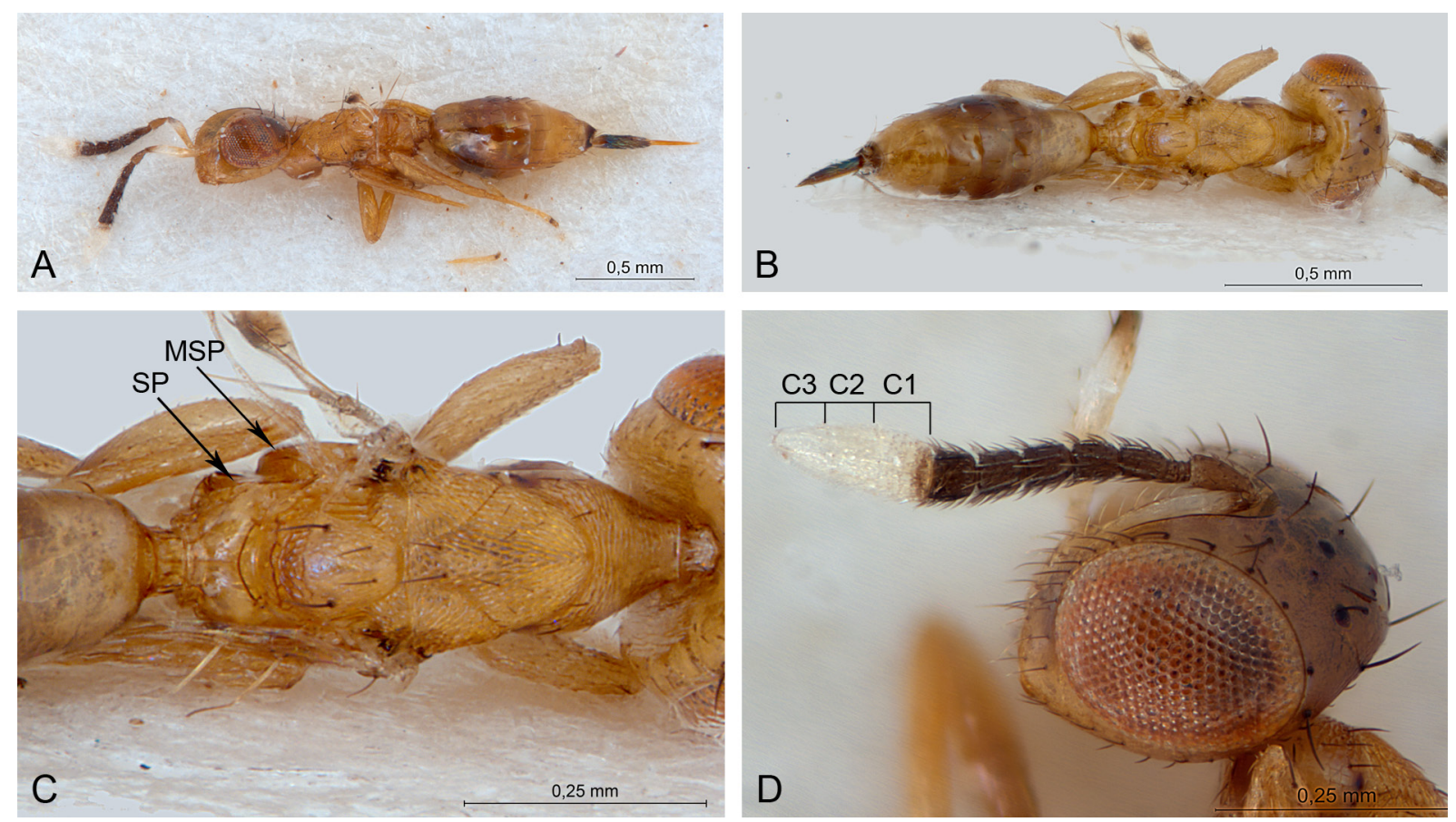

Fig. 5. Diparisca ferrierei: A. $q$, paratype, habitus in lateral view. B. $~+$ (Brazil), habitus in dorsal view. C. + (Brazil), mesosoma in dorsal view. D. $q$ (Brazil), head and left antenna in lateral view. 
differs by having antennae 10-joined [not true, see above], median carina on propodeum, notaulices not meeting in the middle of mesoscutum [Fig. 5C] and mandibles with 2 teeth". I compared Diparisca with Dipara Walker, 1833 and agreed that is a distinct genus, based mainly on the structure of the antenna, the propodeum and the gastral tergites (especially GT1, which is only slightly expanded in Diparisca, as compared with Dipara).

In conclusion, Diparisca appears to be distinct from both Spalangiopelta and Dipara, and is considered here a valid genus. The characteristic shape of the mesosoma in Spalangiopelta (Fig. 3E) and Diparisca (Fig. 5C) is probably a convergence due to the same adaptation to subterranean environments, as suggested by other morphological characteristics, such as the reduction of wings, which is encountered in both genera.

However, the taxonomic placement of Diparisca is problematic. Although the presence of strong bristles is not unique to Diparinae, their configuration on the vertex of diparines apparently is (Desjardins 2007). "In Diparinae, the vertex bristles are arranged along the occipital margin, ocellar triangle, and along the dorso-frontal margins of the eyes" (Desjardins 2007: 20). This is exactly the case in Diparisca (Fig. 5D). The other characters, i.e., the position of propodeal spiracles, the shape of metascutellum, the structure of the cuticle, also point out that the genus is closer to Diparinae than to Ceinae. At the same time, other characters found in Diparisca apparently are closer to Ceinae than to Diparinae, in particular the shape of GT1, which is greatly enlarged in Diparinae (except Pyramidophoriella Hedqvist, 1969), and only moderately so in Diparisca (Fig. 5A-B), and the absence of transverse striation on hind coxae (there are, however, a few diparines that lack striations on hind coxae). The presence or absence of a cercal brush which, according to Desjardins (2007), is always present in Diparinae, could not be determined in the examined specimens of Diparisca. In conclusion, I prefer to keep Diparisca in Diparinae until further evidence.

Darling (1995) stated that the subfamily Ceinae may be a sister group of Diparinae, based on the presence of papilliform sensilla on the antenna. Since then, papilliform sensilla have been discovered also in Pireninae (Mitroiu 2010; Fig. 6), suggesting a common ancestry of Ceinae + Diparinae + Pireninae. Ceinae and Pireninae also share several other morphological features such as the absence of or generally faint, metallic coloration (except some species, including the newly described ones and especially $S$. viridis sp. nov.), low insertion of antennae, and mostly weakly sclerotized, almost smooth cuticule.

In Desjardins' analysis, (Cea + Spalangiopelta) was placed either as a sister-group of (Bohpa + Diparinae) when Bohpa and the bristle positional characters were included in the analysis, or as a sister-group of Coelocybinae, when Bohpa was excluded (Desjardins 2007).

In the most recent phylogenetic analysis of Chalcidoidea (Heraty et al. 2013), Spalangiopelta, the only analyzed genus of the subfamily, appeared to be more related to Tetracampidae and Eulophidae than to other Pteromalidae, but the support for this hypothesis is rather weak.

In conclusion, both the taxonomic placement of Ceinae in relation to other pteromalid subfamilies (especially Diparinae), and their monophyly remain uncertain. Finding additional characters (including molecular ones) could perhaps elucidate these aspects.

\section{Acknowledgments}

I am indebted to the following researchers and curators for their help regarding loans and access to collections: John Noyes, Andrew Polaszek and Natalie Dale-Skey Papilloud (BMNH); Gary Gibson (CNC); José Luis Nieves Aldrey and Mercedes París (MNCN). This work was supported by a grant of 
the Romanian National Authority for Scientific Research, CNCS-UEFISCDI, project number PN-IIRU-TE-2012-3-0057.

\section{References}

Bouček Z. 1953. The 'group Cea' of the chalcidoid family Pteromalidae. Acta Entomologica Musei Nationalis Pragae 28 (407): 157-164.

Darling D.C. 1991a. Bohpa maculata, a new genus and species of Ceinae from South Africa (Hymenoptera: Chalcidoidea: Pteromalidae). Proceedings of the Entomological Society of Washington 93: 622-629. http://www.biodiversitylibrary.org/part/55538

Darling D.C. 1991b. Revision of the World species of Spalangiopelta (Hymenoptera: Chalcidoidea: Pteromalidae: Ceinae). Life Sciences Contributions 155, Royal Ontario Museum, Ontario. http://biodiversitylibrary.org/page/36864648

Darling D.C. 1995. New Palaearctic species of Spalangiopelta (Hymenoptera: Chalcidoidea: Pteromalidae: Ceinae). Canadian Entomologist 127: 225-233.

Darling D.C. 1997. A new species of Spalangiopelta (Hymenoptera; Pteromalidae: Ceinae) from Dominican amber: phylogenetic and biogeographic implications. Journal of the Kansas Entomological Society 69 (4) suppl.: 248-259.

Darling D.C. \& Hanson P.E. 1986. Two new species of Spalangiopelta from Oregon (Hymenoptera: Chalcidoidea), with a discussion of wing length variation. Pan-Pacific Entomologist 62 (2): 153-164.

Desjardins C.A. 2007. Phylogenetics and classification of the world genera of Diparinae (Hymenoptera: Pteromalidae). Zootaxa 1647: 1-88.

Erdős J. 1955. Chalcidoidea nova in collectione Birói (Hymenoptera). Annales Historico-Naturales Musei Nationalis Hungarici (Series Nova) 7: 181-194.

Graham M.W.R. de V. 1966. A new species of Spalangiopelta (Hym., Chalcidoidea, Pteromalidae) from the British Isles. Entomologist 99 (1239): 187-189.

Hedqvist K.J. 1964. Notes in Diparini (Hym., Chalcidoidea, Miscogasteridae). Entomophaga 9 (1): 53-58.

Heraty J.M., Burks R.A., Cruaud A., Gibson G.A.P., Liljebad J., Munro J., Rasplus J.-Y., Delvare G., Jansta P., Gumovsky A., Huber J., Woolley J.B., Krogmann L., Heydon S., Polaszek A., Schmidt S., Darling C., Gates M.W., Mottern J., Murray E., Dal Molin A., Triapitsyn S., Baur H., Pinto J.D., van Noort S., George J. \& Yoder M. 2013. A phylogenetic analysis of the megadiverse Chalcidoidea (Hymenoptera). Cladistics 29: 466-542. http://dx.doi.org/10.1111/cla.12006

Masi L. 1922. Materiali per una fauna dell'Arcipelago Toscano XII. Calcididi del Giglio. Terza serie: Eupelminae (Seguito), Pteromalinae (partim). Annali del Museo Civico di Storia Naturale Giacomo Doria Genova 50: 140-174.

Mitroiu M.-D. 2010. Revision of the Palaearctic species of Macroglenes Westwood (Hymenoptera: Pteromalidae). Zootaxa 2563: 1-34.

Noyes J.S. 2015. Universal Chalcidoidea Database, Natural History Museum London. Available from http://www.nhm.ac.uk/our-science/data/chalcidoids/ [accessed 25 Jan. 2016].

Walker F. 1837. Monographia Chalciditum (Continued). Entomological Magazine 4 (4): 349-364.

Yoshimoto C.M. 1977. A new species of Spalangiopelta Masi in North America (Chalcidoidea: Pteromalidae, Ceinae). Canadian Entomologist 109 (4): 541-544. http://dx.doi.org/10.4039/Ent109541-4 
Manuscript received: 11 March 2016

Manuscript accepted: 2 May 2016

Published on: 15 December 2016

Topic editor: Gavin Broad

Desk editor: Laurence Bénichou

Printed versions of all papers are also deposited in the libraries of the institutes that are members of the EJT consortium: Muséum national d'Histoire naturelle, Paris, France; Botanic Garden Meise, Belgium; Royal Museum for Central Africa, Tervuren, Belgium; Natural History Museum, London, United Kingdom; Royal Belgian Institute of Natural Sciences, Brussels, Belgium; Natural History Museum of Denmark, Copenhagen, Denmark; Naturalis Biodiversity Center, Leiden, the Netherlands. 